\title{
High Vitamin D Levels May Downregulate Inflammation in Patients with Behçet's Disease
}

\author{
Fahd Adeeb, ${ }^{1,2,3,4}$ Maria Usman Khan, ${ }^{1,2,3}$ Xia Li, ${ }^{2,5}$ Austin G. Stack, ${ }^{2,3,6}$ \\ Joseph Devlin, ${ }^{1}$ and Alexander D. Fraser ${ }^{1,2,3}$ \\ ${ }^{1}$ Department of Rheumatology, University Hospital Limerick, Limerick, Ireland \\ ${ }^{2}$ Graduate Entry Medical School, University of Limerick, Limerick, Ireland \\ ${ }^{3}$ Health Research Institute, University of Limerick, Ireland \\ ${ }^{4}$ Department of Medicine, Universiti Teknologi MARA, Sungai Buloh, Selangor, Malaysia \\ ${ }^{5}$ Department of Mathematics and Statistics, La Trobe University, Melbourne, VIC, Australia \\ ${ }^{6}$ Department of Nephrology, University Hospital Limerick, Limerick, Ireland \\ Correspondence should be addressed to Fahd Adeeb; fahd_adeeb@yahoo.com
}

Received 16 February 2017; Revised 1 May 2017; Accepted 9 May 2017; Published 4 June 2017

Academic Editor: Jian-Dong Li

Copyright (C) 2017 Fahd Adeeb et al. This is an open access article distributed under the Creative Commons Attribution License, which permits unrestricted use, distribution, and reproduction in any medium, provided the original work is properly cited.

\begin{abstract}
Vitamin D plays a significant role in the immune system modulation and may confer a protective role in autoimmune diseases. We conducted a case-control study to compare $25(\mathrm{OH}) \mathrm{D}$ levels in patients with $\mathrm{BD}$ who were managed at a regional rheumatology programme in the midwest region of Ireland compared to matched controls. Healthy controls were selected from the Irish health system and matched in 1:5 ratio for age, sex, and the month of the year. $25(\mathrm{OH}) \mathrm{D}$ levels $<20 \mathrm{nmol} / \mathrm{L}$ were classified as deficient while levels between 20 and $40 \mathrm{nmol} / \mathrm{L}$ were classified as insufficient. Differences between groups were assessed using Mann-Whitney test and associations between cases and controls were expressed as odds ratios and 95\% confidence intervals. Nineteen patients with BD were compared with 95 controls matched by age, sex, and month of blood draw. $25(\mathrm{OH}) \mathrm{D}$ levels were significantly higher in patients in BD than in matched controls (median values: $45 \mathrm{nmol} / \mathrm{L}$ versus $22 \mathrm{nmol} / \mathrm{L}, p<0.005$ ) and tended to be lower in patients with active disease than in those without (median values: $35 \mathrm{nmol} / \mathrm{L}$ (IQR: $22.75-47.25 \mathrm{~nm} / \mathrm{L}$ ) versus $50 \mathrm{nmol} / \mathrm{L}$ (IQR: $35-67 \mathrm{nmol} / \mathrm{L}$ ), $p=0.11)$. Compared to controls, patients with $\mathrm{BD}$ were significantly less likely to have $25(\mathrm{OH}) \mathrm{D}$ deficiency or insufficiency $(\mathrm{OR}$ : $0.09,95 \%$ CI: $0.03-0.28, p<0.001)$. Our findings suggest a possible role for $25(\mathrm{OH}) \mathrm{D}$ in modifying the inflammatory response in $\mathrm{BD}$ and uncover a potential opportunity to assess whether correction of Vit $\mathrm{D}$ deficiency confers protective benefits.
\end{abstract}

\section{Introduction}

Behçet's disease $(\mathrm{BD})$ is classified among vasculitides with a unique characteristic of having a predilection for both arteries and veins and manifesting with distinct clinical characteristics. Despite having a considerable geographical variation with the highest prevalence seen along the Silk Road, BD is seen throughout the world including European countries with latitudes above $45^{\circ}$ north. Ireland is a country with a temperate maritime climate strongly influenced by the Atlantic Ocean due to its proximity at the periphery of northwest Europe at a high latitude of $51-55^{\circ}$ north, with a relatively low sunshine exposure throughout the year [1].
Vitamin D (Vit D) is a major fat-soluble vitamin that is essential for normal immune function and a large body of evidence now implicates Vit $\mathrm{D}$ in the pathogenesis of several inflammatory diseases including BD [2-16]. The main source of Vit D is from the ultraviolet B- (UVB-) induced synthesis in the skin, which is then activated via two hydroxylation steps in the liver and kidney. Studies have shown that exposing $5 \%$ of the body surface in fair-skinned persons 2 to 3 times a week for 5 minutes of noontime summer sun exposure is equivalent to intake of $430 \mathrm{IU} / \mathrm{d}$ of Vit $\mathrm{D}$, which satisfies the recommended Vit D intake of $200 \mathrm{IU} / \mathrm{d}$ for young adults [17]. The recommended intake is $400 \mathrm{IU} / \mathrm{d}$ for persons aged 51 to 70 years and $600 \mathrm{IU} / \mathrm{d}$ for those above 70 years of age [18]. 
A serum Vit D level of $\geq 30 \mathrm{ng} / \mathrm{mL}(75 \mathrm{nmol} / \mathrm{L})$ is considered adequate to limit the release of parathyroid hormone or promote the intestinal absorption of calcium $[19,20]$.

Recent studies from Mediterranean countries and the Far East have uncovered potentially important links between Vit $\mathrm{D}$ and $\mathrm{BD}$ [9-16, 21-23]. Interestingly, the findings indicate an inverse correlation between Vit D and BD [9-15] with higher levels of Vit D correlating with lower levels of disease activity $[12,14,16]$. It is hypothesized that low levels of Vit D suppress T-regulatory cells (Tregs) activity, cause skewing of the Th1/Th2 balance towards Th1, and impair endothelial function $[10,12]$. However, not all studies have confirmed this association. Observational studies from Turkey and Tunisia found no significant differences between Vit D levels in cases with $\mathrm{BD}$ and matched healthy controls [21, 22], while contrastingly a study from Iran found higher Vit D levels among patients with $\mathrm{BD}[23]$.

The aim of our study was to determine the relationship between Vit D status and BD in an Irish population and assess whether Vit D levels varied according to disease activity. This study is the first to explore the association between Vit D and BD in a Northern European population.

\section{Methods}

2.1. Study Design. We conducted a case-control study of patients with $\mathrm{BD}$ and compared them to healthy controls selected from the Irish health system. Cases included all patients with BD who were managed in a regional rheumatology programme at University Hospital Limerick, a tertiary centre located in the midwest region of Ireland. All cases satisfied the International Study Group Criteria for Behçet's Disease (ISGBD) or the International Criteria for Behçet's Disease (ICBD). Medical records and electronic data including clinical and laboratory parameters of all cases were reviewed. Exclusion criteria include other rheumatological or bone/skeletal diseases or other diseases with higher inflammatory status, history of chronic kidney disease or other chronic systemic diseases, malignancies, and limited physical activity. Patients were also excluded if they received Vit D supplementation or medications that interfered with Vit D metabolism including calcium supplements, cytotoxic drugs, anticonvulsants, bisphosphonates, or thyroxine, but not glucocorticoids and disease-modifying antirheumatic drugs (DMARDs). Active disease in BD was defined as the presence of any characteristic symptoms including mucocutaneous, visceral, ocular, or skin lesions necessitating initiation or dose increment of systemic steroids and/or immunosuppressive therapy. Healthy controls $(n=95)$ were selected from a register of patients in the health system from years 2013 and 2014. Blood samples from controls were matched with cases based on age, sex, and month of blood draw in a 1:5 ratio. Control subjects had normal concentrations of serum creatinine, haemoglobin, and serum albumin.

2.2. Vitamin D Assessment. Total serum 25-hydroxyvitamin D $(25(\mathrm{OH}) \mathrm{D})$ level was measured by using competitive chemiluminescence immunoassays (DiaSorin, Dietzenbach, Germany) with interassay coefficient of variation (CV) of
$6.8 \%[24,25]$. Levels less than $20 \mathrm{nmol} / \mathrm{L}$ were defined as Vit D deficient and between 20 and $40 \mathrm{nmol} / \mathrm{L}$ as Vit D insufficient, with "normal" defined as levels more than $40 \mathrm{nmol} / \mathrm{L}$. The study was approved by the local ethics committee and is in accordance with the Declaration of Helsinki.

2.3. Statistical Analysis. Vit D levels were not normally distributed; therefore, median and interquartile ranges were used to describe distributions between cases and controls. Nonparametric statistics (Mann-Whitney $U$ test) were used to compare serum Vit D levels between patients and controls. Odds ratios (OR) and 95\% confidence intervals (95\% CI) were used to determine the likelihood of Vit D deficiency and Vit $\mathrm{D}$ insufficiency for cases versus controls using multivariate logistic regression. $p$ values of $<0.05$ were considered statistically significant. Statistical analyses were performed using SPSS 22.0 software for Macintosh.

\section{Results}

A total of 19 Caucasian patients with $\mathrm{BD}$ were included in the study sample (5 males, 14 females, median age of 37.5 years, interquartile range (IQR): $24.3-51.2$ years). 15 patients were in clinical remission while 4 patients had evidence of active disease. Baseline characteristics of the study population are reported in Tables 1 and 2. There were no statistically significant differences between cases and the control group with regard to age, sex, and time of blood draw. Disease duration varied between 0.25 and 30 years (mean: 8.07 years).

Median serum concentrations of $25(\mathrm{OH}) \mathrm{D}$ for patients with $\mathrm{BD}$ and controls were $45 \mathrm{nmol} / \mathrm{L}$ (IQR: $33-65 \mathrm{nmol} / \mathrm{L}$ ) and $22 \mathrm{nmol} / \mathrm{L}$ (IQR: $15-31 \mathrm{nmol} / \mathrm{L}$ ), respectively, $p<0.005$. The median 25(OH)D levels also tended to be lower among patients with active $\mathrm{BD}$ as compared to those with inactive disease, $35 \mathrm{nmol} / \mathrm{L}$ (IQR: $22.75-47.25 \mathrm{nmol} / \mathrm{L}$ ) and $50 \mathrm{nmol} / \mathrm{L}$ (IQR: $35-67 \mathrm{nmol} / \mathrm{L})$, respectively, but this did not reach statistical significance $(p$ value $=0.11)$ (Table 3$)$. Similarly, the prevalence of $25(\mathrm{OH}) \mathrm{D}$ deficiency and insufficiency was significantly lower in BD compared to matched controls $(0 \%$ versus $42 \%$ for $25(\mathrm{OH}) \mathrm{D}$ deficiency and $6 \%$ versus $36 \%$ for 25(OH)D insufficiency, $p<0.005)$.

In the unadjusted analysis, compared to controls, patients with BD were significantly less likely to have $25(\mathrm{OH}) \mathrm{D}$ deficiency or insufficiency with the unadjusted analysis odds ratio (OR) $0.10(0.03,0.30)$. With adjustment for age, sex, and month of blood draw, the relationship was even more robust (OR: $0.09(0.03,0.28), p<0.001)$. Women were more likely than men to have Vit D deficiency (OR: 3.01, 95\% CI: 1.10-8.26) (Table 4).

\section{Discussion}

In this Irish study, we report significant differences in the concentrations of Vit $\mathrm{D}$ levels among patients with $\mathrm{BD}$ compared to healthy controls from the health system. In keeping with the previous Iranian study [23], our study found significantly and substantially higher $25(\mathrm{OH}) \mathrm{D}$ levels in patients with BD than in those without. The magnitude of the difference was quite substantial and our analysis indicated 
TABLE 1: Demographics and clinical characteristics of BD patients and healthy controls.

\begin{tabular}{|c|c|c|c|}
\hline Variables & BD patients $(n=19)$ & Controls $(n=95)$ & $p$ value \\
\hline Age (years) & 37.5 & 37.4 & 0.924 \\
\hline Median (Q1-Q3) & $(24.3-51.2)$ & $(24.1-51.4)$ & \\
\hline Female, $n(\%)$ & $14(73.68)$ & $70(73.68)$ & N/A \\
\hline Serum 25(OH)D levels (median) (nmol/L) & 45.0 & 22.0 & 0.001 \\
\hline IQR (Q1-Q3) & $(33.0-65.0)$ & $(15.0-31.0)$ & \\
\hline $25(\mathrm{OH}) \mathrm{D}$ deficiency $(<20 \mathrm{nmol} / \mathrm{L}), n(\%)$ & $0(0)$ & $42(44.2)$ & \\
\hline $25(\mathrm{OH}) \mathrm{D}$ insufficiency $(20-40 \mathrm{nmol} / \mathrm{L}), n(\%)$ & $6(31.6)$ & $36(37.9)$ & \\
\hline On prednisolone, $n(\%)$ & $8(42.1)$ & Nil & N/A \\
\hline$<7.5$ mg daily, $n(\%)$ & $8(42.1)$ & & \\
\hline$\geq 7.5 \mathrm{mg}$ daily, $n(\%)$ & $0(0)$ & & \\
\hline DMARDs, $n(\%)$ & $15(78.9)$ & Nil & N/A \\
\hline On conventional DMARD, $n(\%)$ & $0(0)$ & & \\
\hline On anti-TNF therapy, $n(\%)$ & $15(78.9)$ & & \\
\hline
\end{tabular}

Values are median and IQR, or numbers $(n)$ and percentage (\%) for counts. 25(OH)D: 25-hydroxyvitamin D; N/A: not applicable; IQR: interquartile range; Q1: 25th quartile; Q3: 75th quartile.

TABLE 2: Patients' clinical characteristics, treatment, and their vitamin D status.

\begin{tabular}{|c|c|c|c|c|c|c|c|c|c|c|c|c|c|c|}
\hline Number & G & Age & OA & $\mathrm{GU}$ & OI & $\mathrm{CI}$ & $\mathrm{PP}$ & VI & GI & ENT & DA & $25(\mathrm{OH}) \mathrm{D}$ & ESR & CRP \\
\hline 1 & $\mathrm{~F}$ & 33 & + & + & - & + & - & - & - & + & - & 76 & 6 & $<5$ \\
\hline 2 & M & 51 & + & + & + & + & + & - & + & + & - & 71 & 7 & 7 \\
\hline 3 & $\mathrm{~F}$ & 35 & + & + & - & + & - & - & - & + & A & 42 & 25 & 5 \\
\hline 4 & $\mathrm{~F}$ & 23 & + & + & - & + & - & - & - & + & - & 45 & 11 & $<5$ \\
\hline 5 & $\mathrm{~F}$ & 17 & + & + & + & + & - & - & - & - & - & 50 & 6 & $<5$ \\
\hline 6 & M & 48 & + & + & + & + & - & + & - & - & - & 65 & 12 & $<5$ \\
\hline 7 & M & 56 & + & - & + & + & - & - & - & + & - & 58 & 2 & $<5$ \\
\hline 8 & $\mathrm{~F}$ & 37 & + & + & - & + & - & - & - & - & - & 67 & 12 & $<5$ \\
\hline 9 & $\mathrm{~F}$ & 38 & + & + & - & - & + & - & - & - & - & 41 & 8 & $<5$ \\
\hline 10 & M & 34 & + & + & - & + & - & - & - & - & - & 76 & 17 & $<5$ \\
\hline 11 & $\mathrm{~F}$ & 37 & + & + & - & + & - & - & - & - & - & 33 & 5 & $<5$ \\
\hline 12 & F & 52 & + & + & - & + & - & + & - & - & A & 28 & 28 & $<5$ \\
\hline 13 & F & 81 & + & + & + & + & - & - & - & - & - & 41 & 14 & $<5$ \\
\hline 14 & $\mathrm{~F}$ & 66 & + & + & - & + & - & - & + & - & - & 35 & 33 & $<5$ \\
\hline 15 & $\mathrm{M}$ & 45 & + & + & - & - & - & + & - & - & - & 29 & 7 & $<5$ \\
\hline 16 & $\mathrm{~F}$ & 37 & + & + & - & + & - & - & - & - & A & 21 & 28 & 25 \\
\hline 17 & F & 23 & + & + & + & + & - & - & - & - & - & 53 & 5 & $<5$ \\
\hline 18 & F & 21 & + & + & - & + & - & - & - & - & - & 26 & 13 & $<5$ \\
\hline 19 & $\mathrm{~F}$ & 24 & + & + & - & + & - & - & - & - & A & 49 & 14 & $<5$ \\
\hline
\end{tabular}

G: gender; OA: oral aphthosis; GU: genital ulcers; OI: ocular involvement; CI: cutaneous involvement; PP: pathergy phenomenon; VI: vascular involvement; GI: gastrointestinal involvement; ENT: otolaryngeal involvement; DA: disease activity; A: active disease; 25(OH)D: 25-hydroxyvitamin D (nmol/L); ESR: erythrocyte sedimentation rate ( $\mathrm{mm} /$ hour); CRP: C-reactive protein $(\mathrm{mg} / \mathrm{L})$.

TABLE 3: Comparison of 25(OH)D levels between patients with active and inactive Behçet's disease.

\begin{tabular}{|c|c|c|c|}
\hline Variables & Active $\mathrm{BD}(n=4)$ & Inactive $\mathrm{BD}(n=15)$ & $p$ value \\
\hline Serum 25(OH)D levels (median) (nmol/L) & 35.0 & 50.0 & 0.11 \\
\hline (IQR1-IQR3) & $(21.0-42.0)$ & $(35.0-67.0)$ & \\
\hline $25(\mathrm{OH}) \mathrm{D}$ deficiency $(<20 \mathrm{nmol} / \mathrm{L}), n(\%)$ & $0(0)$ & $0(0)$ & \\
\hline $25(\mathrm{OH}) \mathrm{D}$ insufficiency $(20-40 \mathrm{nmol} / \mathrm{L}), n(\%)$ & $2(50.0)$ & $4(26.7)$ & \\
\hline
\end{tabular}


TABLE 4: Odds ratio of 25(OH)D deficiency in cases versus controls.

\begin{tabular}{|c|c|c|c|c|}
\hline Variables & Unadjusted OR (95\% CI) & $p$ value & Adjusted OR (95\% CI) & $p$ value \\
\hline \multicolumn{5}{|l|}{ Sex } \\
\hline Female versus male & $2.44(1.00,6.00)$ & 0.051 & $3.01(1.1,8.26)$ & 0.032 \\
\hline \multicolumn{5}{|l|}{ Group } \\
\hline Cases (with BD) versus controls & $0.10(0.03,0.30)$ & $<0.001$ & $0.09(0.03,0.28)$ & $<0.001$ \\
\hline
\end{tabular}

that patients with $\mathrm{BD}$ were over 10 -fold less likely to have Vit D deficiency compared to controls without BD. Moreover, our study also suggested that patients with active BD tended to have lower Vit D levels compared to those with inactive disease. Our findings suggest a possible role for $25(\mathrm{OH}) \mathrm{D}$ in modifying the inflammatory response in $\mathrm{BD}$ and uncover a potential opportunity to assess whether correction of Vit D deficiency confers protective benefits.

The finding of higher concentrations of Vit D in patients with $\mathrm{BD}$ compared to control patients was an unusual yet intriguing observation. The threshold value of Vit $\mathrm{D}$ considered to be adequate for human health is $50 \mathrm{nmol} / \mathrm{L}$ and therefore the majority of both BD patients and controls had levels that were below this threshold limit [26]. Notwithstanding this, cases with BD experienced significantly higher levels than controls without the disease. Even more intriguing is the observation that patients with active BD tended to have lower Vit D levels than those without. It is possible that higher levels of Vit D are immunomodulatory and downregulate inflammatory pathways commonly associated with BD and thereby are protective against disease flares. The small sample size clearly makes it difficult to demonstrate significance but our observations support the findings from other published studies $[12,14,16]$ and suggest that serum concentrations of $25(\mathrm{OH}) \mathrm{D}$ in subjects with $\mathrm{BD}$ correlate inversely with disease activity.

Another interesting finding in our study is that the majority of subjects in the control group were either Vit D insufficient or deficient. Ireland is located at the high latitudes of $51-55^{\circ}$ north and receives between 1100 and 1600 hours of sunshine each year [27]. Due to its geographical position in Northwest Europe and its proximity to the Atlantic Ocean resulting in a low-pressure system and moderation of the climate, Ireland is said to have a maritime climate where summers are not too hot and winters are not too cold. The average amount of rainfall in the western region of Ireland is up to 225 days a year while the cloud immersion almost completely covers the skies for more than 50 percent of the time [27]. These combined factors together with possible uses of sunscreens ultimately result in inadequate quantity and ineffective quality of UV irradiation that may explain why hypovitaminosis $\mathrm{D}$ abounds within the Irish population $[28,29]$.

Vit D contributes to the regulation of the proliferation, differentiation, and function of immune cells, both directly and indirectly [30-32]. The perspective role of Vit D as an immunoregulatory hormone stemmed from in vitro studies of its metabolism by immune cells in the early 1980s [33, 34] and was further supported by the works of Fritsche and Van Etten and their respective colleagues who identified the Vit
D receptor (VDR) in the immune cells such as neutrophils, dendritic cells, and activated lymphocytes [35], proving that Vit $\mathrm{D}$ was potently able to modulate a range of immune cell functions [36], respectively.

Vit D has been shown to enhance the effect of dendritic cells, macrophages, and monocytes and has been demonstrated to downregulate cellular response to tumor necrosis factor-alpha (TNF- $\alpha$ ), B-cell antibody production, and proinflammatory cytokines such as interleukin-1 (IL1), IL-2, IL-6, IL-12, and interferon-gamma (IFN- $\gamma$ ) [3742]. Its receptor, $\mathrm{VDR}$, is a nuclear hormone receptor that regulates the $\mathrm{p} 450$ enzymes and interacts with various interconnected lipid metabolism and immune signaling pathways that have instrumental roles in immunity including peroxisome proliferator-activated receptor-alpha (PPAR- $\alpha$ ), PPAR$\gamma, \mathrm{NF}-\kappa \mathrm{B}, \mathrm{p} 38$ mitogen-activated protein kinase (MAPK), transforming growth factor-beta (TGF- $\beta$ ), and eicosanoid synthesis [43]. It is also a ligand-regulated transcription factor of many target genes, namely, the natural endogenous antimicrobial peptides (AMPs) cathelicidin and $\beta$-defensin: both crucial in shaping the gut microbiota [43], barrier defense, and maintaining the integrity of the gut mucosa $[44,45]$. These overall immunoregulatory effects underline Vit D as a key mediator of innate and adaptive immunity.

In addition, there has also been a paradigm shift regarding the different functions of Vit D, including its essential role in the skin [46-51]. Skin cells such as keratinocytes and fibroblasts express VDR, an absolute prerequisite for regulation of genomic effects of Vit D and its other analogs [47]. A randomized, double-blind placebo-controlled study demonstrated that Vit D supplementation resulted in a significant improvement in parameters of diabetic foot ulcers at 12 weeks compared to placebo [48]. Other studies have demonstrated the positive effect of Vit D in tissue formation and remodeling [49-51]. The recurrent, relapsing, and remitting nature of Behçet's disease (BD), especially the orogenital ulcers and cutaneous manifestations, and the fact that wound healing is a dynamic process which involves phases of inflammation, tissue formation, and remodeling [52] implicate Vit D as possibly one of the key players in the pathogenesis of BD.

The Vit D pathway is now strongly implicated to be involved in the pathogenesis of inflammatory diseases such as inflammatory arthritis, lupus, and BD [2-16]. Furthermore, VDR gene polymorphisms have been observed to be significantly associated with an increased susceptibility risk in different BD populations [53-56]. Recently, Kahraman et al. demonstrated elevated numbers of circulating extracellular vesicles (EVs), novel mediators of distant cellular communication in $\mathrm{BD}$ patients, and observed significantly higher levels of cathelicidin in plasma of active BD patients, with 
two-thirds of them being associated with the EVs and cytokine production, correlating them with the disease activity [57].

Gut microbiota (GM) dysbiosis characterized by the reduction of the GM ecosystem diversity and composition has been implicated in the proinflammatory features of several autoimmune disorders including immunological diseases outside of the gut [58, 59], and this impaired microbiome-host interaction seems to play a role in the pathogenesis of BD [60-62]. Recently, Wang et al. in their comprehensive analysis of genome-wide host-microbiota associations discovered significant associations between gut microbial characteristics and the VDR gene [63]. In another study, Yuk et al. demonstrated cathelicidin as the link between autophagy and Vit D mediated innate immunity [64]. The relationship between autophagy, which not just maintains the gut intracellular homeostasis but also promotes immunity in symbiosis with the VDR, and the gut microbiota shapes the intestinal immune response and the disarray of this interaction may play a crucial part in the pathogenesis of BD.

We acknowledge some inherent limitations in the present study and consequently definitive conclusions are limited. First, the relatively small sample size of our cohort with $\mathrm{BD}$ and the variability in the duration of disease posed a limitation in our study. However, the number of patients in this study is an accurate reflection of the low prevalence of BD in this Northern European geographical region. Further studies including collaborative efforts involving other $\mathrm{BD}$ cohorts may provide a greater insight into this specific area. Second, our analysis may be confounded by other factors such as body mass index and the differences in the sun exposure of cases (and controls) which may vary according to lifestyle, the use of sunscreen, and overall health. Third, we were also unable to adjust for season variation in Vit D as the study was conducted over 10 months to coincide with outpatient visits. However, we attempted to account for this confounder in our analysis by limiting the selection of controls only to those who had Vit D levels assessed during the same time period.

The strength of our study is the comparison with a control population who were selected from patients within the health system based on age, gender, and timing of taking the sample. Despite insufficient and inconclusive evidence in the literature, there is a growing appreciation and basis to suggest that Vit D supplementation could represent an essential adjuvant treatment in active inflammatory patients who are also found to be deficient or insufficient of Vit D. The results of our study, despite its limitations, may provide some basis to support this hypothesis. Further intervention studies however are needed to prove a beneficial effect of Vit $\mathrm{D}$ supplementation among BD patients.

In summary, our study found evidence of elevated $25(\mathrm{OH}) \mathrm{D}$ levels in patients with $\mathrm{BD}$ compared to controls in the health system. Patients with $\mathrm{BD}$ were over 10-fold less likely to have Vit D deficiency adjusting for age, sex, and timing of blood samples. Vit D levels tended to be also lower among those with active disease than among those without. Our findings suggest that Vit D may be a potential suppressor of the inflammatory response in $\mathrm{BD}$. The contribution of Vit $\mathrm{D}$ to the pathogenesis of $\mathrm{BD}$ and as a therapeutic intervention deserves further investigation. Studies of larger size are required to explore the hypothesis suggested here.

\section{Disclosure}

An earlier version of this work was presented as an abstract at the 17th International Conference on Behçet's Disease on 15-17 September 2016 in Matera, Italy, and at the 37th European Workshop for Rheumatology Research on 2-4 March 2017 in Athens, Greece.

\section{Conflicts of Interest}

All authors have no conflicts of interest to report.

\section{References}

[1] A. Kazantzidis, A. Smedley, R. Kift, J. Rimmer, J. L. Berry, L. E. Rhodes et al., "A modeling approach to determine how much UV radiation is available across the UK and Ireland for health risk and benefit studies," Photochemical and Photobiological Sciences, vol. 14, p. 1073, 2015.

[2] L. E. Jeffery, K. Raza, and M. Hewison, "Vitamin D in rheumatoid arthritis-towards clinical application," Nature Reviews Rheumatology, vol. 12, no. 4, pp. 201-210, 2016.

[3] L. Andreoli, S. Piantoni, F. Dall'Ara, F. Allegri, P. L. Meroni, and A. Tincani, "Vitamin D and antiphospholipid syndrome," Lupus, vol. 21, no. 7, pp. 736-740, 2012.

[4] Y. H. Lee and S. C. Bae, "Vitamin D level in rheumatoid arthritis and its correlation with the disease activity: a meta-analysis," Clinical and Experimental Rheumatology, vol. 34, pp. 827-833, 2016.

[5] M. Mouyis, A. J. Ostor, A. J. Crisp, A. Ginawi, D. J. Halsall, N. Shenker et al., "Hypovitaminosis D among rheumatology outpatients in clinical practice," Rheumatology, vol. 47, no. 9, pp. 1348-1351, 2008.

[6] S. Patel, T. Farragher, J. Berry, D. Bunn, A. Silman, and D. Symmons, "Association between serum vitamin D metabolite levels and disease activity in patients with early inflammatory polyarthritis," Arthritis \& Rheumatism, vol. 56, no. 7, pp. 2143-2149, 2007.

[7] J. A. Reynolds, A. Z. Rosenberg, C. K. Smith, J. C. Sergeant, G. I. Rice, T. A. Briggs et al., "Brief report: vitamin D deficiency is associated with endothelial dysfunction and increases type I Interferon gene expression in a murine model of systemic lupus erythematosus," Arthritis \& Rheumatology, vol. 68, no. 12, pp. 2929-2935, 2016.

[8] P. Gatenby, R. Lucas, and A. Swaminathan, "Vitamin D deficiency and risk for rheumatic diseases: an update," Current Opinion in Rheumatology, vol. 25, no. 2, pp. 184-191, 2013.

[9] S. Karatay, K. Yildirim, A. Karakuzu, A. Kiziltunc, R. I. Engin, Y. B. Eren et al., "Vitamin D status in patients with behcet's disease," Clinics, vol. 66, pp. 721-723, 2011.

[10] M. Can, M. Gunes, O. A. Haliloglu et al., "Effect of vitamin D deficiency and replacement on endothelial functions in Behçet's disease," Clinical and Experimental Rheumatology, vol. 30, no. 3, supplement 72, pp. S57-S61, 2012.

[11] A. Khabbazi, N. Rashtchizadeh, A. Ghorbanihaghjo et al., "The status of serum vitamin $\mathrm{D}$ in patients with active Behcet's 
disease compared with controls," International Journal of Rheumatic Diseases, vol. 17, no. 4, pp. 430-434, 2014.

[12] K. Hamzaoui, I. Ben Dhifallah, E. Karray, F. H. Sassi, and A. Hamzaoui, "Vitamin D modulates peripheral immunity in patients with Beh $\tau$ et's disease," Clinical and Experimental Rheumatology, vol. 28, no. 4, supplement 60, pp. S50-S57, 2010.

[13] N. Aslan, K. Demirci, T. Güler, F. Dörtbaş, and E. Kale, “The effect of vitamin $\mathrm{D}$ on clinical manifestations and activity of Behçet's disease," Advances in Dermatology and Allergology, vol. 34, pp. 15-20, 2017.

[14] S. S. Ganeb, H. H. Sabry, M. M. El-Assal, H. M. Kamal, and A. A. Fayed, "Vitamin D levels in patients with behçet's disease: significance and impact on disease measures," Egyptian Rheumatologist, vol. 35, no. 3, pp. 151-157, 2013.

[15] Z. Al-Nahas, M. Fawzy, M. El Menyawi, O. Shaker, and G. Ragab, "25-hydroxyvitamin D3 deficiency and vitamin D receptor polymorphisms in Egyptian patients with Behçet's disease: a pilot study," International Journal of Clinical Rheumatology, vol. 12, pp. 20-27, 2017.

[16] J. E. Do, S. Y. Kwon, S. Park, and E.-S. Lee, "Effects of vitamin D on expression of Toll-like receptors of monocytes from patients with Behçet's disease," Rheumatology, vol. 47, no. 6, pp. 840-848, 2008.

[17] Standing Committee on the Scientific Evaluation of Dietary Reference Intake, Dietary Reference Intakes: Calcium, Phosphorus, Magnesium, Vitamin D, and Fluoride, National Academies Press, Washington, DC, Wash, USA, 1997.

[18] J. K. Robinson, "Sun exposure, sun protection, and vitamin D," Journal of the American Medical Association, vol. 294, no. 12, pp. 1541-1543, 2005.

[19] M. Audran and K. Briot, "Critical reappraisal of vitamin D deficiency," Joint Bone Spine, vol. 77, no. 2, pp. 115-119, 2010.

[20] M. F. Holick, "Vitamin D deficiency," The New England Journal of Medicine, vol. 357, no. 3, pp. 266-281, 2007.

[21] B. Kandi, D. Cicek, and N. Ilhan, "Vitamin levels in Behçet's disease," Journal of Dermatological Treatment, vol. 18, no. 2, pp. 69-75, 2007.

[22] M. Kechida, O. Harzallah, I. Hellara, R. Klii, F. Naffeti, M. F. Najjar et al., "Vitamin D status of Behcet's patients. analysis of correlation with activity and severity of the disease as well as with the quality of life of patients," International Archives of Medicine, vol. 251, pp. 1-7, 2015.

[23] S. T. Faezi, N. Ansari, P. Paragomi, M. Akhlaghi, M. Ghanavat, and F. Davatchi, "Vitamin D deficiency in patients with Behcet's disease," Journal of Diabetes and Metabolic Disorders, vol. 13, no. 1 , article 18, 2014.

[24] B. Ireland, "Primary Sample Manual-Clinical Chemistry," 2016.

[25] A. M. Wallace, S. Gibson, A. de la Hunty, C. Lamberg-Allardt, and M. Ashwell, "Measurement of 25-hydroxyvitamin D in the clinical laboratory: current procedures, performance characteristics and limitations," Steroids, vol. 75, no. 7, pp. 477-488, 2010.

[26] A. C. Ross, C. L. Taylor, A. L. Yaktine, and H. B. Del Valle, Eds., etary References Intakes for Calcium and Vitamin D, The National Academies Press, Washington, DC, wash, USA, 2011.

[27] E. Gleeson, R. McGrath, and M. Treanor, Eds., Ireland's Climate: The Road Ahead, Dublin, Ireland, 2013, http://hdl.handle.net/ 2262/71304.

[28] E. Lardner, M. Fitzgibbon, S. Wilson, D. Griffin, and E. Mulkerrin, "Hypovitaminosis D in a healthy female population, aged from 40 to 85 years, in the west of Ireland," Irish Journal of Medical Science, vol. 180, no. 1, pp. 115-119, 2011.
[29] K. D. Cashman, S. Muldowney, B. McNulty et al., "Vitamin D status of Irish adults: findings from the National Adult Nutrition Survey," British Journal of Nutrition, vol. 109, no. 7, pp. 12481256, 2013.

[30] X. Guillot, L. Semerano, N. Saidenberg-Kermanac'h, G. Falgarone, and M.-C. Boissier, "Vitamin D and inflammation," Joint Bone Spine, vol. 77, no. 6, pp. 552-557, 2010.

[31] M. Bscheider and E. C. Butcher, "Vitamin D immunoregulation through dendritic cells," Immunology, vol. 148, no. 3, pp. 227236, 2016.

[32] I. Szymczak and R. Pawliczak, "The active metabolite of vitamin D3 as a potential immunomodulator," Scandinavian Journal of Immunology, vol. 83, no. 2, pp. 83-91, 2016.

[33] A. K. Bhalla, E. P. Amento, T. L. Clemens, M. F. Holick, and S. M. Krane, "Specific high-affinity receptors for 1,25dihydroxyvitamin D3 in human peripheral blood mononuclear cells: presence in monocytes and induction in T lymphocytes following activation," Journal of Clinical Endocrinology and Metabolism, vol. 57, no. 6, pp. 1308-1310, 1983.

[34] D. M. Provvedini, C. D. Tsoukas, L. J. Deftos, and S. C. Manolagas, "1,25-Dihydroxyvitamin D3 receptors in human leukocytes," Science, vol. 221, no. 4616, pp. 1181-1183, 1983.

[35] J. Fritsche, K. Mondal, A. Ehrnsperger, R. Andreesen, and M. Kreutz, "Regulation of 25-hydroxyvitamin D3-1 alphahydroxylase and production of 1 alpha 25-dihydroxyvitamin D3 by human dendritic cells," Blood, vol. 102, no. 9, pp. 3314-3316, 2003.

[36] E. Van Etten, B. Decallonne, L. Verlinden, A. Verstuyf, R. Bouillon, and C. Mathieu, "Analogs of $1 \alpha, 25$-dihydroxyvitamin D3 as pluripotent immunomodulators," Journal of Cellular Biochemistry, vol. 88, no. 2, pp. 223-226, 2003.

[37] K. Bahar-Shany, A. Ravid, and R. Koren, "Upregulation of MMP-9 production by TNF $\alpha$ in keratinocytes and its attenuation by vitamin D," Journal of Cellular Physiology, vol. 222, no. 3, pp. 729-737, 2009.

[38] M. Linker-Israeli, E. Elstner, J. R. Klinenberg, D. J. Wallace, and H. P. Koeffler, "Vitamin D3 and its synthetic analogs inhibit the spontaneous in vitro immunoglobulin production by SLEderived PBMC," Clinical Immunology, vol. 99, no. 1, pp. 82-93, 2001.

[39] E. Laird, H. McNulty, M. Ward et al., "Vitamin D deficiency is associated with inflammation in older irish adults," Journal of Clinical Endocrinology and Metabolism, vol. 99, no. 5, pp. 18071815, 2014.

[40] D. D’Ambrosio, M. Cippitelli, M. G. Cocciolo et al., "Inhibition of IL-12 production by 1,25-dihydroxyvitamin D3. Involvement of NF- $\kappa \mathrm{B}$ downregulation in transcriptional repression of the p40 gene," Journal of Clinical Investigation, vol. 101, no. 1, pp. 252-262, 1998.

[41] C. Almerighi, A. Sinistro, A. Cavazza, C. Ciaprini, G. Rocchi, and A. Bergamini, " $1 \alpha, 25$-dihydroxyvitamin D3 inhibits CD40L-induced pro-inflammatory and immunomodulatory activity in human monocytes," Cytokine, vol. 45, no. 3, pp. 190197, 2009.

[42] A. Giulietti, E. van Etten, L. Overbergh, K. Stoffels, R. Bouillon, and C. Mathieu, "Monocytes from type 2 diabetic patients have a pro-inflammatory profile. 1,25-Dihydroxyvitamin D3 works as anti-inflammatory," Diabetes Research and Clinical Practice, vol. 77, no. 1, pp. 47-57, 2007.

[43] H. Newmark, W. Dantoft, and P. Ghazal, "Evolutionary origin of the interferon-immune metabolic axis: the sterol-vitamin D link," Frontiers in Immunology, vol. 8, p. 62, 2017. 
[44] P. T. Liu, S. Stenger, H. Li, L. Wenzel, B. H. Tan, S. R. Krutzik et al., "Toll-like receptor triggering of a vitamin D-mediated human antimicrobial response," Science, vol. 311, pp. 1770-1773, 2006.

[45] J. H. White, "Vitamin D as an inducer of cathelicidin antimicrobial peptide expression: past, present and future," Journal of Steroid Biochemistry and Molecular Biology, vol. 121, no. 1-2, pp. 234-238, 2010.

[46] P. H. Hart, S. Gorman, and J. J. Finlay-Jones, "Modulation of the immune system by UV radiation: more than just the effects of vitamin D?" Nature Reviews Immunology, vol. 11, no. 9, pp. 584596, 2011.

[47] B. Lehmann, "The vitamin D3 pathway in human skin and its role for regulation of biological processes," Photochemistry and Photobiology, vol. 81, no. 6, pp. 1246-1251, 2005.

[48] R. Razzaghi, H. Pourbagheri, M. Momen-Heravi et al., "The effects of vitamin D supplementation on wound healing and metabolic status in patients with diabetic foot ulcer: a randomized, double-blind, placebo-controlled trial," Journal of Diabetes and its Complications, vol. 31, no. 4, pp. 766-772, 2017.

[49] J. Ding, P. Kwan, Z. Ma et al., "Synergistic effect of vitamin D and low concentration of transforming growth factor beta 1 , a potential role in dermal wound healing," Burns, vol. 42 , no. 6 , pp. 1277-1286, 2016.

[50] N. López-López, I. González-Curiel, M. B. Treviño-Santa Cruz et al., "Expression and vitamin D-mediated regulation of matrix metalloproteinases (MMPs) and tissue inhibitors of metalloproteinases (TIMPs) in healthy skin and in diabetic foot ulcers," Archives of Dermatological Research, vol. 306, no. 9, pp. 809-821, 2014.

[51] Y. Oda, C. L. Tu, A. Menendez, T. Nguyen, and D. D. Bikle, "Vitamin D and calcium regulation of epidermal wound healing," The Journal of Steroid Biochemistry and Molecular Biology, vol. 164, pp. 379-385, 2016.

[52] A. J. Singer and R. A. Clark, "Cutaneous wound healing," The New England Journal of Medicine, vol. 341, no. 10, pp. 738-746, 1999.

[53] A. Kamal, S. M. Gamal, F. T. Elgengehy, A. K. Alkemary, and I. Siam, "Association of VDR ApaI and TaqI gene polymorphisms with the risk of scleroderma and Behçet's disease," Immunological Investigations, vol. 45, no. 6, pp. 531-542, 2016.

[54] E. F. Karray, I. Ben Dhifallah, K. Ben Abdelghani et al., "Associations of vitamin D receptor gene polymorphisms FokI and BsmI with susceptibility to rheumatoid arthritis and Behçet's disease in Tunisians," Joint Bone Spine, vol. 79, no. 2, pp. 144-148, 2012.

[55] S. Kolahi, A. Khabbazi, H. Khodadadi et al., "Vitamin D receptor gene polymorphisms in Iranian Azary patients with Behçet's disease," Scandinavian Journal of Rheumatology, vol. 44, no. 2, pp. 163-167, 2015.

[56] G. Erten, M. Kalkan, S. Bilgiç Gazioğlu, N. Akdeniz, E. Ozkok, and B. Vural, "TaqI, FokI, and ApaI polymorphisms in the Vitamin D receptor in Behçet's disease in Turkish population," Disease Markers, vol. 2016, pp. 1-6, 2016.

[57] T. Kahraman, G. Gucluler, I. Simsek, F. C. Yagci, M. Yildirim, C. Ozen et al., "Circulating LL37 targets plasma extracellular vesicles to immune cells and intensifies Behçet's disease severity," Journal of Extracellular Vesicles, vol. 6, Article ID 1284449, 2017.

[58] N. Cerf-Bensussan and V. Gaboriau-Routhiau, "The immune system and the gut microbiota: friends or foes?" Nature Reviews Immunology, vol. 10, pp. 735-744, 2010.
[59] D. J. Cua and J. P. Sherlock, “Autoimmunity's collateral damage: gut microbiota strikes 'back," Nature Medicine, vol. 17, no. 9, pp. 1055-1056, 2011.

[60] C. Consolandi, S. Turroni, G. Emmi et al., "Behçet's syndrome patients exhibit specific microbiome signature," Autoimmunity Reviews, vol. 14, no. 4, pp. 269-276, 2015.

[61] M. M. D’Elios, M. Benagiano, A. Amedei, and G. Emmi, "Infections, autoimmunity, and Behçet's syndrome: what liaison?" in Behçet's Syndrome, Rare Diseases of The Immune System, Rare Diseases of the Immune System, pp. 39-51, Springer-Verlag, Milano, Italia, 2014.

[62] J. Shimizu, T. Kubota, E. Takada et al., "Bifidobacteria abundance-featured gut microbiota compositional change in patients with behcet's disease," PLOS ONE, vol. 11, no. 4, Article ID e0153746, 2016.

[63] J. Wang, L. B. Thingholm, J. Skiecevičienè, P. Rausch, M. Kummen, J. R. Hov et al., "Genome-wide association analysis identifies variation in vitamin $\mathrm{D}$ receptor and other host factors influencing the gut microbiota," Nature Genetics, vol. 48, no. 11, pp. 1396-1406, 2016.

[64] J. Yuk, D. Shin, H. Lee et al., "Vitamin D3 induces autophagy in human monocytes/macrophages via cathelicidin," Cell Host and Microbe, vol. 6, no. 3, pp. 231-243, 2009. 


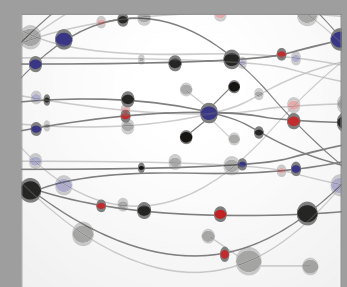

The Scientific World Journal
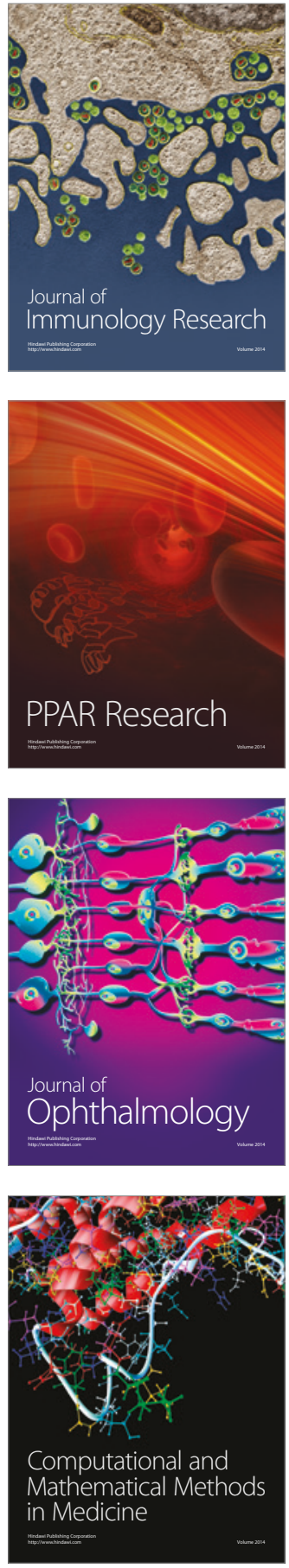

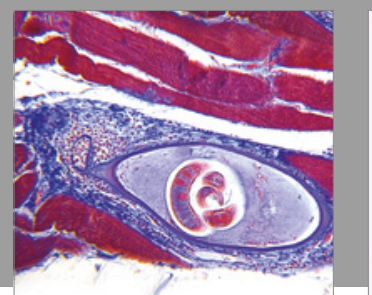

Gastroenterology Research and Practice
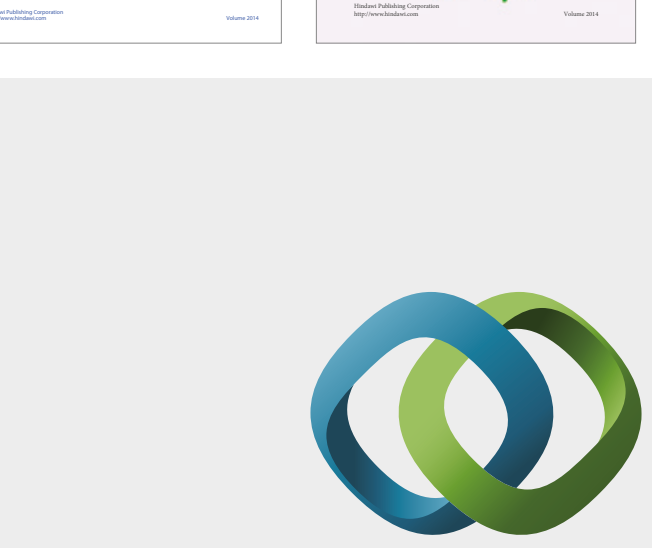

\section{Hindawi}

Submit your manuscripts at

https://www.hindawi.com
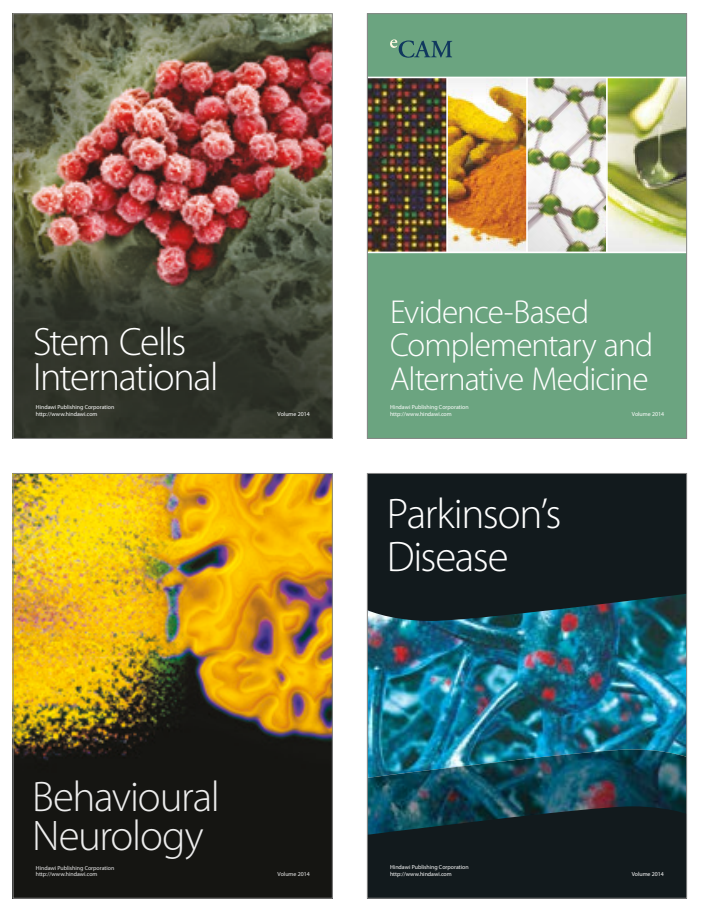
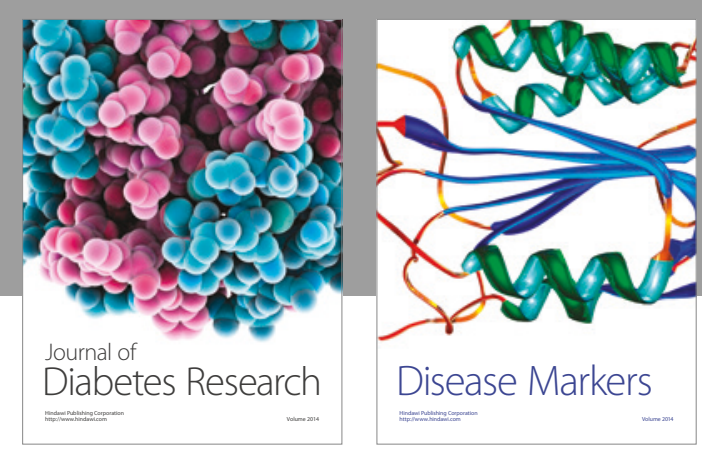

Disease Markers
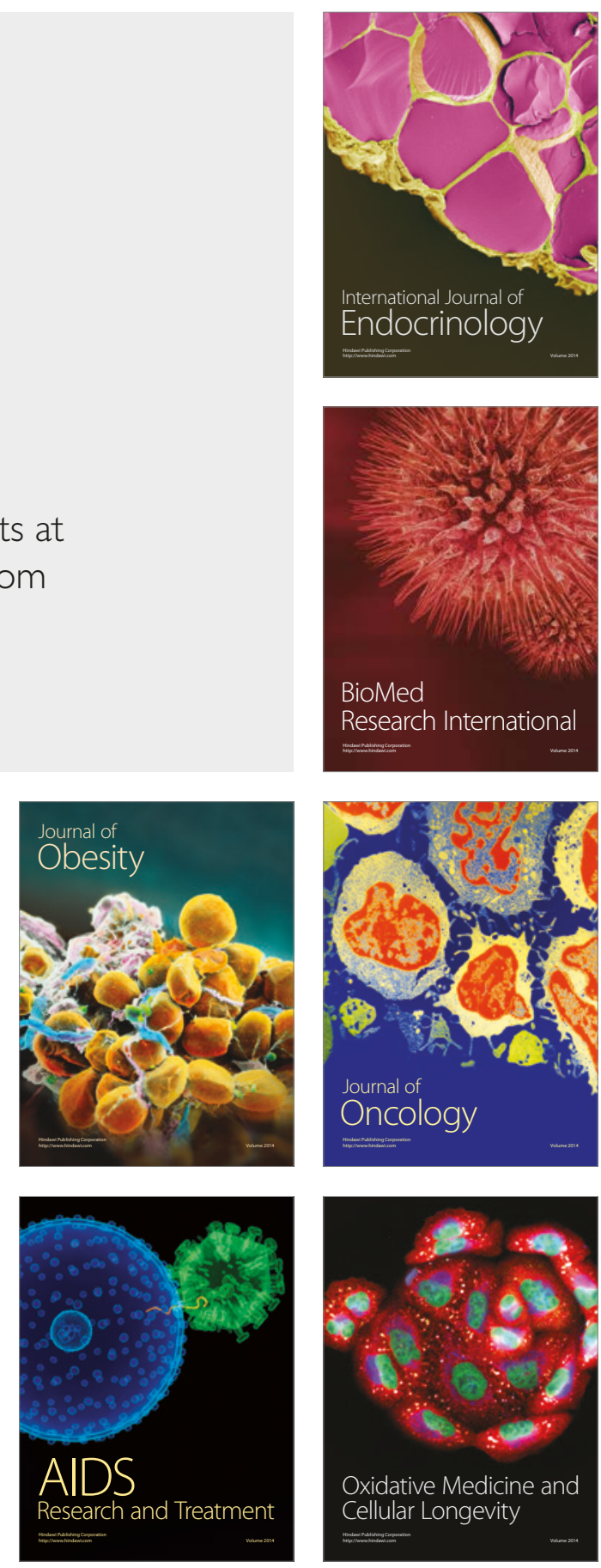